\title{
Repair of Pre-cracked Reinforced Concrete (RC) Beams with Openings Strengthened Using FRP Sheets Under Sustained Load
}

\author{
Bashir H. Osman ${ }^{1,2), *}$, Erjun $\mathrm{Wu}^{1)}$, Bohai $\mathrm{Ji}^{1)}$, and Suhaib S. Abdulhameed ${ }^{1)}$
}

(Received April 22, 2016, Accepted November 17, 2016, Published online February 28, 2017)

\begin{abstract}
Strengthening reinforced concrete (RC) beams with openings by using aramid fiber reinforcement polymers (AFRP) on the beams' surfaces offers a useful solution for upgrading concrete structures to carry heavy loads. This paper presents a repairing technique of the AFRP sheets that effectively strengthens RC beams, controls both the failure modes and the stress distribution around the beam chords and enhances the serviceability (deflection produced under working loads be sufficiently small and cracking be controlled) of pre-cracked RC beams with openings. To investigate the possible damage that was caused by the service load and to simulate the structure behavior in the site, a comprehensive experimental study was performed. Two unstrengthened control beams, four beams that were pre-cracked before the application of the AFRP sheets and one beam that was strengthened without pre-cracking were tested. Cracking was first induced, followed by repair using various orientations of AFRP sheets, and then the beams were tested to failure. This load was kept constant during the strengthening process. The results show that both the preexisting damage level and the FRP orientation have a significant effect on strengthening effectiveness and failure mode. All of the strengthened specimens exhibited higher capacities with capacity enhancements ranging from 21.8 to $66.4 \%$, and the crack width reduced by $25.6-82.7 \%$ at failure load compared to the control beam. Finally, the authors present a comparison between the experimental results and the predictions using the ACI 440.2R-08 guidelines.
\end{abstract}

Keywords: pre-cracked, RC beaam, AFRP strengthening, beam with openings.

\section{Introduction}

Transverse openings in reinforced concrete $(\mathrm{RC})$ beams are facilities that allow for the passage of utility lines through a structure. Due to sudden changes presented in the cross section of the beam, the opening edges are, for the most part, subjected to high stress concentrations, which inadvertently leads to induced transverse cracks in the beam; resulting in a significant reduction in the beam shear capacity and stiffness (Mansur 1998; Mansur et al. 1999; Yang et al. 2006). The external bonding of different materials, such as high-strength fiber reinforced plastics (FRP) or steel plates, has gained wide popularity in recent years to strengthen the RC structural (Hawileh et al. 2012).

In recent years, FRP has been increasingly used as a substitute for traditional steel reinforcements in RC structures due to its superior material properties, such as; light weight, immunity to the corrosive effects of acids, alkalis, salts and

\footnotetext{
${ }^{1)}$ College of Civil and Transportation Engineering, Hohai University, Nanjing 210098, China.

*Corresponding Author; E-mail: bashir00@yahoo.com

${ }^{2)}$ Civil Engineering Department, College of Engineering, University of Sinnar, Sinnar, Sudan.

Copyright $($ The Author(s) 2017. This article is published with open access at Springerlink.com
}

similar aggressive materials under wide range of temperature, and excellent mechanical strength and stiffness (Deborah 1994). These advantages account for the FRP's superior strength when compared with alternative materials such as steel plates, steel rods or FRP reinforcing bars (rebars) (Lin and Zhang 2013). Furthermore, it has been found that the orientation of the FRP also plays a significant role in the behavior of RC beams and failure mode (Singh 2013). The external plate bonding technique for structural rehabilitation is now well established as a convenient repair method for increasing the shear strength and stiffness of reinforced concrete beams. The advantage of this technique is the speed of the upgrading process, which makes the technique more economical in most cases compared with other strengthening techniques, such as concrete jacketing or complete replacement of the member. More importantly, this repair technique can be performed while the structure is still in use (Hussein et al. 2013). Within the past decade, there has been numerous studies conducted regarding the strength and behavior of RC deep beams with openings (Ashour and Rishi 2000; Campione and Minafò 2012; El Maaddawy and Sherif 2009; Mansur and Alwis 1984; Shanmugam and Swaddiwudhipong 1988; Zhang et al. 2004). Hussain and Pimanmas (2015) conducted an extensive experimental program to elevate the shear strength of RC deep beams with openings strengthened with Sprayed Glass Fiber Reinforced Polymer (SGFRP) composites. Both circular and square openings of varying sizes were investigated. To prevent debonding 
failures, a mechanical anchoring system was introduced to secure the SGFRP to the beam's surface. They reported that the failure mode was changed from debonding to inclined crack rupture in the fibers due to the presence of anchor bolts. Alternatively, El Maaddawy and Sherif (2009) examined the potential use of externally bonded carbon fiber reinforced polymer (CFRP) composite sheets as a strengthening solution to upgrade reinforced concrete (RC) deep beams with openings. The strength gain caused by the CFRP sheets was in the range of $35-73 \%$. Furthermore, others studies have reported a significant increase in both shear strength and stiffness when the RC deep beams with openings are bonded by fiber reinforced polymer (FRP) system; whilst limiting the resulting shear crack width within these beams (Chaallal et al. 2002; Dias and Barros 2008; Etman 2011; Hoult and Lees 2009). The results of these investigations have demonstrated the effectiveness of different opening geometries and different FRP systems such as sheet, wrap and strips to attain the desired effects. It should be noted that most studies presented in literature focus on the shear behavior and strength of RC shallow beams with openings (Mansur 2006; Osman et al. 2016; Torunbalci 2002; Aykac et al. 2013).

Two different pre-repair loading histories in RC beams were simulated by Richardson and Fam (2014) using cracking within the elastic range and overloading in the plastic range. Their beams were repaired with either high or ultrahigh modulus (210 or $400 \mathrm{GPa}$ ) carbon fiber reinforced polymer (CFRP) sheets or a hybrid sheet and were then reloaded to failure. Alternatively, tests conducted by El-Ashkar et al. (2012) showed that loading the beams to their first cracking loads before the application of FRP sheets strengthening has virtually no effect on the repair efficiency; however, no discussions were found on the effect of increasing the preloading level and the associated increase in crack width and length. The experimental and FE-method-based studies modeling the effect of various pre-cracked loads on the shear behavior of FRP-strengthened RC deep beams with openings are scarce. However, very few researchers have considered pre-cracked $\mathrm{RC}$ beams that have been strengthened in terms of shear via externally bonded FRP reinforcement (Dirar et al. 2013; Vecchio and Bucci 1999; Kim and Vecchio 2008).

Accordingly, no researchers have investigated the potential use of an externally bonded AFRP system as an external repair upgrade of pre-cracked RC deep beams with openings under sustained load. This paper demonstrates that the AFRP-strengthening sheets can significantly increase the efficiency of pre-cracked RC deep beam with openings. The experimental data provided by this paper helps to gain a better understanding and enhance the experimental database of the shear behavior of preloaded RC deep beams with openings strengthened with the AFRP sheet.

\section{Experimental Program}

For the experimental investigation, seven rectangular reinforced concrete beams with openings (the openings were created before concrete casting using circular tubes) were fabricated and tested. Two un-strengthened control beams were considered, four beams that were pre-cracked before the application of the AFRP sheets and one beam that was strengthened without pre-cracking were tested. Cracking was first induced, and then repairs were performed using an epoxy injection with varying orientations of the AFRP sheets, followed by testing of the beams to failure. This load was kept constant during the strengthening process till full curing of the AFRP epoxy adhesive; once the epoxy had cured, it was continuously loaded till failure of the beam. The following sections provide details of the experimental program.

\subsection{Test Specimens and Parameters}

In this paper, a total of seven RC deep beam specimens with circular openings were tested. The specimens included five repaired beams and two control beams (solid and with opening) without strengthening. All specimens had a rectangular cross section of $120 \mathrm{~mm}$ wide and $300 \mathrm{~mm}$ high, with a total length of $1800 \mathrm{~mm}$. All beams were tested under a shear span-to-depth ratio of 1.6 in order to ensure that deep beam action will develop. The specimens had a similar default internal shear reinforcement that was designed to ensure failure in shear. To guarantee that shear failure would occur only within the shear span of all of the beams, the internal longitudinal reinforcement (tension steel) was increased in the bottom of the beam. Steel stirrups of 6-mmdiameter spaced every $100 \mathrm{~mm}$ were implemented as shear reinforcement. All tension and compression reinforcement were kept the same for all the specimens. Two of the $20-\mathrm{mm}$ diameter deformed bars were used as bottom reinforcement (in tension the face), and two of $10 \mathrm{~mm}$ deformed bars were used as top reinforcement. Details and dimensions (in $\mathrm{mm}$ ) of the test beams are shown in Fig. 1.

A clear cover at the top and bottom of the beam was $20 \mathrm{~mm}$, whereas a clear cover of $15 \mathrm{~mm}$ was maintained on the beam's vertical sides. All specimens had two circular openings, one in each shear span, that were placed symmetrically about the mid-point of the beam (Fig. 1). The opening size was $140 \mathrm{~mm}$, which corresponded to opening height-to-effective depth ratio of 0.5 . The beams were cast in a horizontal position using plywood molds.

Table 1 summarizes the test matrix, including various parameters. Specimen B1 and B2 were considered control beams and were tested to failure load without any damaging or AFRP strengthening, and B3 was strengthened with AFRP sheets and loaded to failure without preloading. Specimens B4 and B5 were brought to a damage level within the elastic range by cracking up to $50 \%$ of the failure load of the control beam (B2) and were then strengthened with different AFRP schemes. Beam B6 was strengthened with AFRP after being loaded up to $70 \%$ of B2, and beam $\mathrm{B} 7$ was loaded as in beam B6, but the load was released to the cracking load of the control beam (B2). The load was kept constant during the strengthening process in beams B4B7. The strengthening process was took at least three days 


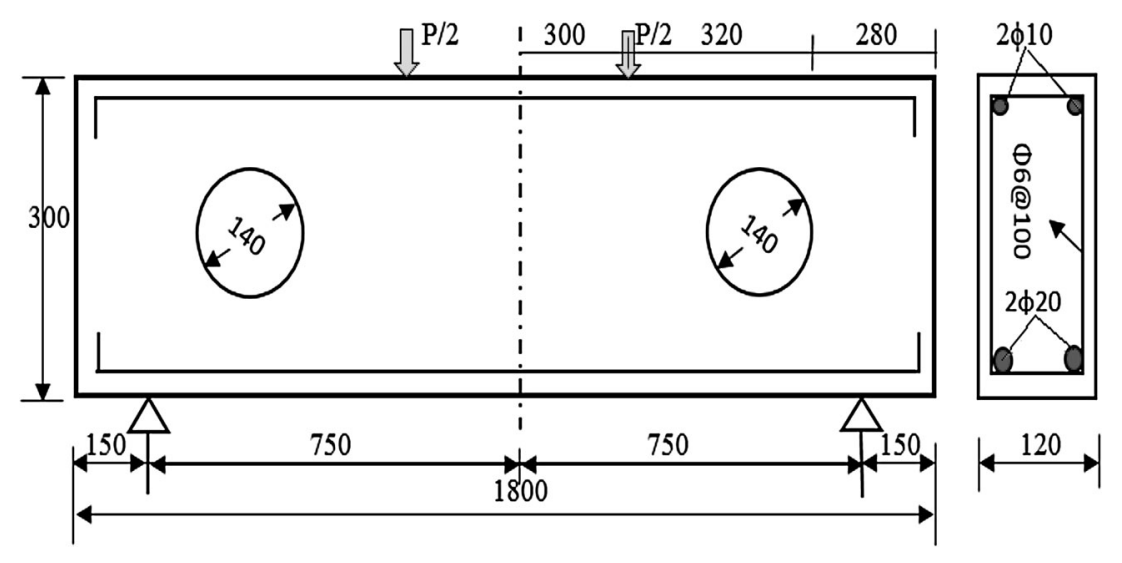

Fig. 1 Specimen's details (in $\mathrm{mm}$ ).

Table 1 Test matrix.

\begin{tabular}{|c|c|c|c|c|c|}
\hline No & Damage level & FRP strengthening & FRP orientation & $\mathrm{F}_{\mathrm{c}}^{\prime}\left(\mathrm{N} / \mathrm{mm}^{2}\right)$ & Opening size $\mathrm{mm}$ \\
\hline B1 & - & - & - & 39.3 & - \\
\hline B2 & - & - & - & 39.3 & $0.5 \mathrm{~d}$ \\
\hline B3 & - & U wrap & Vertical & 39.3 & $0.5 \mathrm{~d}$ \\
\hline B4 & $50 \%$ of $\mathrm{B} 2$ & U wrap & Vertical & 39.3 & $0.5 \mathrm{~d}$ \\
\hline B5 & $50 \%$ of $\mathrm{B} 2$ & U wrap & Diagonal & 39.3 & $0.5 \mathrm{~d}$ \\
\hline B6 & $70 \%$ of $\mathrm{B} 2$ & U wrap & Diagonal & 39.3 & $0.5 \mathrm{~d}$ \\
\hline B7 & $70 \%$ of $\mathrm{B} 2$ & U wrap & Diagonal & 39.3 & $0.5 \mathrm{~d}$ \\
\hline
\end{tabular}

(72 h) to ensure full curing of AFRP epoxy (Abdulhameed et al. 2013).

The AFRP sheets were applied to three faces of the beam in a $U$ wrap shape and had a consistent bond length of $350 \mathrm{~mm}$, a $120 \mathrm{~mm}$ width and a $300 \mathrm{~mm}$ height. Specimens B3 and B4 were strengthened with vertical AFRP, and the diagonal AFRP $\left(60^{\circ}\right)$ was used in the other beams (B5-B7). Figure 2 presents the layout of the AFRP sheet arrangements on the beam faces.

\subsection{Materials' Properties}

The properties of the steel reinforcement and the concrete that were used in this research were obtained experimentally. All test beams were prepared at the same time and cured under the same conditions to ensure that the compressive strength was approximate in nature. The cube's compressive strength was obtained by testing nine cubes with dimensions of $150 \times 150 \times 150 \mathrm{~mm}$ using Compressive Testing Machine (CTM). The average tested compressive strength of

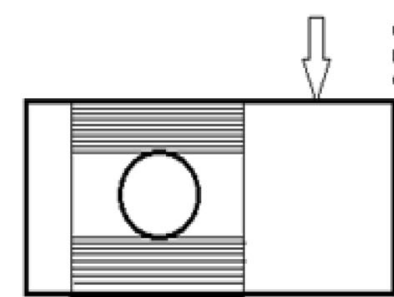

(a)
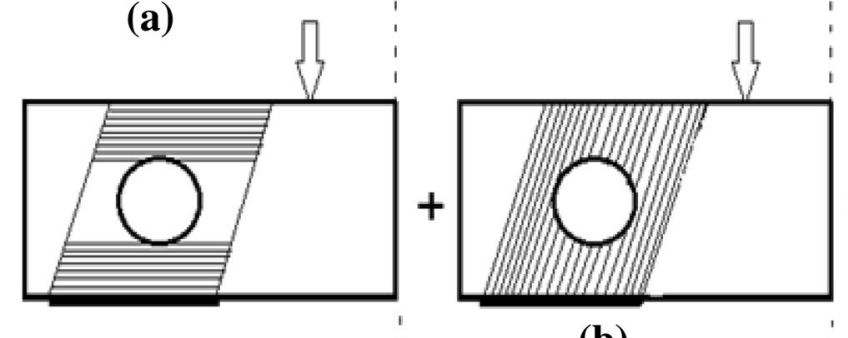

(b)

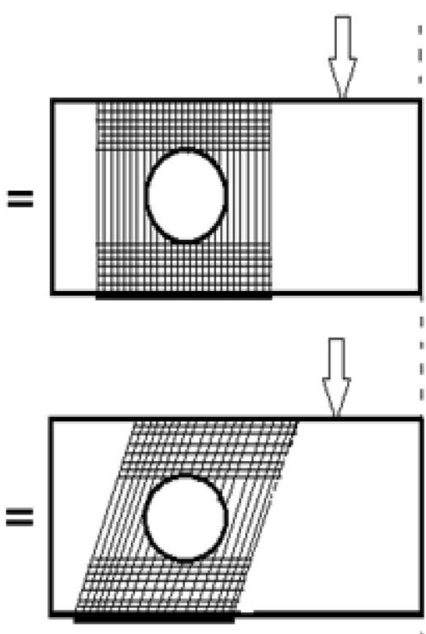

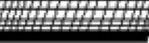

Fig. 2 AFRP layout a $U$ wrap vertical strengthening (B3 and B4), b $U$ wrap diagonal strengthening (B5-B7). 
concrete at 28 days was $39.3 \mathrm{MPa}$. The yield strength of steel reinforcement was obtained by testing three bars with diameters of $\phi 20 \mathrm{~mm}, \phi 10 \mathrm{~mm}$ and $\phi 6 \mathrm{~mm}$, respectively, using Tensile Testing Machine (TTM). The longitudinal steel reinforcement was Grade 480 and 450 deformed steel bars for tension $(\phi 20 \mathrm{~mm})$ and compression $(\phi 10 \mathrm{~mm})$ reinforcement, respectively, and the web reinforcement was Grade 330 deformed bars. The AFRP sheet (type C1-AK-40) has a tensile strength of $2100 \mathrm{MPa}$, an elastic modulus of $120 \mathrm{GPa}$, and a thickness of $0.193 \mathrm{~mm}$. The properties of the epoxy adhesive, primer, putty, and FRP were provided by the manufacturers and are given in Table 2.

\subsection{Specimen Preparations and Test Setup}

The concrete surface was prepared before the bonding of the U-shaped AFRP sheets. The three surfaces of the beam were sandblasted and cleaned before FRP application until the aggregates were exposed. The corners of the beam were rounded with a radius of $10 \mathrm{~mm}$ to avoid stress concentration in the $U$ wrap. Longitudinal AFRP sheets that were $60 \mathrm{~mm}$ wide by $350 \mathrm{~mm}$ long were bonded to the concrete chords above and below each opening, with the fibers oriented in a direction parallel to the longitudinal axis of the beam (Fig. 2) to prevent any delamination occurring during shear that would have concentrated in the chords.

The surface dust was removed by an air blower. Next, the surface was cleaned with acetone. A thin layer of primer [type Telesun Epoxy Adhesive (TLS)-501] was applied to the prepared surface of the reinforced concrete beam. The primer was allowed to cure for $24 \mathrm{~h}$ before the epoxy adhesive was applied to the concrete. The purposes of the primer are as follows: to strengthen the surface of the concrete, prevent the epoxy from being absorbed by the concrete instead of wetting fibers, penetrate the concrete via the pores, and enhance the bond for the fibers. Putty is used to fill larger holes and irregularities on the surface of the concrete. A layer of epoxy adhesive (TLS-503) was applied by a paintbrush to the surface of the concrete and AFRP sheet (Abdulhameed et al. 2013).

All beams were tested under four-point bending in the structural testing frame, as shown in Fig. 3. To provide bearing and frictionless rotational, the beams were supported on two heavy-duty rollers during the test. The clear span between the supports was $1500 \mathrm{~mm}$. The beams were subjected to two monotonic loadings using a steel spreader beam that conveyed the load from a $500-\mathrm{kN}$ capacity jack to the beam. The load was measured by a $500-\mathrm{kN}$ capacity load cell. The load was applied at an increment of $5 \mathrm{kN}$ using the load cell machine. The distance between the loads was $600 \mathrm{~mm}$. The deflection values were recorded at each load increment up to failure. The load that caused the crack was recorded, and its crack pattern was marked on the beam surfaces (Fig. 4).

\subsection{Instrumentation of LVDTs and Strain Gauges}

The tested RC beams were instrumented with linear variable differential transducers (LVDTs) to monitor the deflection and the crack width during the test (Fig. 3). The deflection during testing was measured using LVDTs located under the two load points and at mid-span. Measurements of the strains in the reinforcing bars and concrete were made using electrical-resistance strain gauges with gauge lengths of 5 and $100 \mathrm{~mm}$, respectively, as shown in Fig. 3a. Strains in the AFRP were made using electrical-resistance strain gauges with gauge lengths of $5 \mathrm{~mm}$, as shown in Fig. $3 \mathrm{~b}$.

\section{Experimental Results and Discussions}

\subsection{Failure Mode and Cracks Pattern}

Table 3 gives a summary of the load capacity and failure modes of all of the tested beams. The observation of specimens during the tests and detailed discussions are presented in the following. It was noted that the control beam B1 experienced failure due to the shearing off of the concrete in the load path, located between the load points and the supports, as illustrated in Fig. 6. As the load increased, inclined diagonal shear cracks (at approximately $45^{\circ}$ from the supports) appeared at the line connecting the load points and the supports. A further load increase resulted in the widening of diagonal cracks as well as the initiation of new flexural and diagonal cracks, whereas the shear cracks were inactive. Due to failure in the shear region, the beam finally failed at a load of $251 \mathrm{kN}$. The load-mid-span deflection curve and the failure mode of the beam are illustrated in Figs. 5 and 6, respectively.

Beam B2, which was tested to failure without strengthening, failed at a load $50 \%$ lower than that of the control beam B1. Failure occurred by shear off of the concrete. The

Table 2 Material Properties.

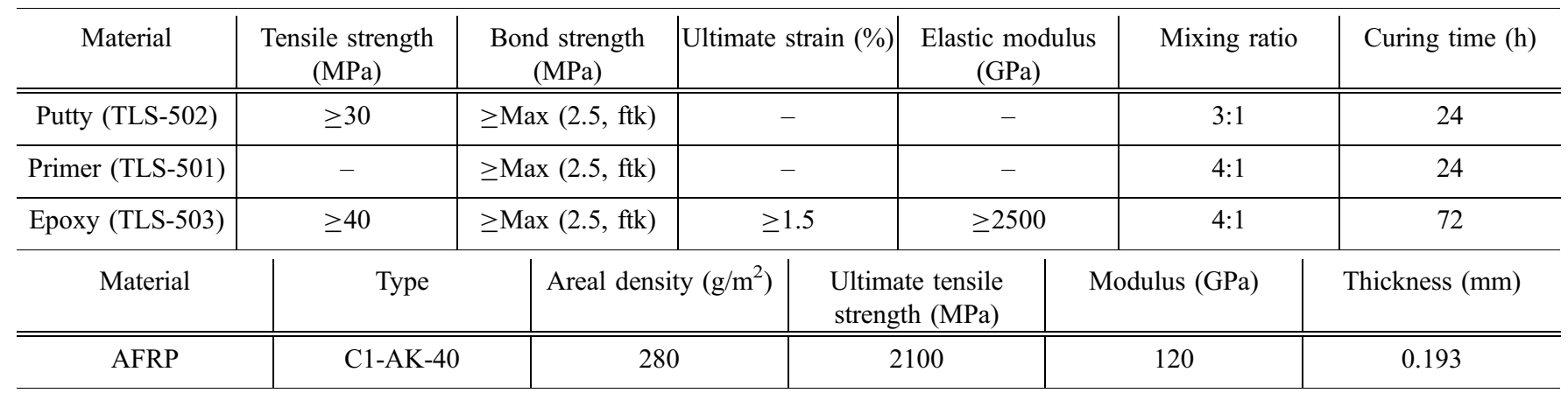



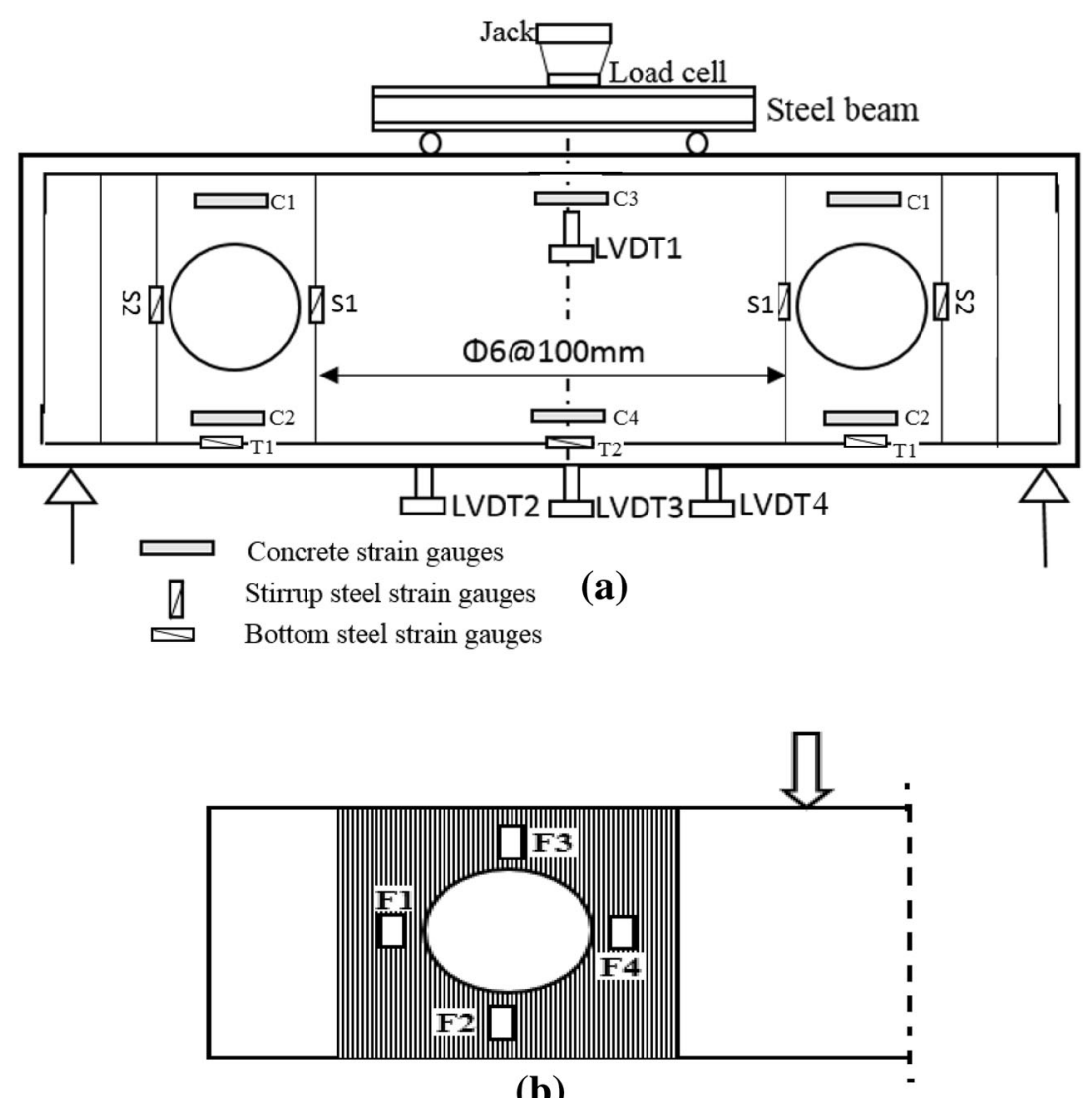

(b)

Fig. 3 Test setup a LVDT positions and steel strain gauges and b AFRP strain gauges location.

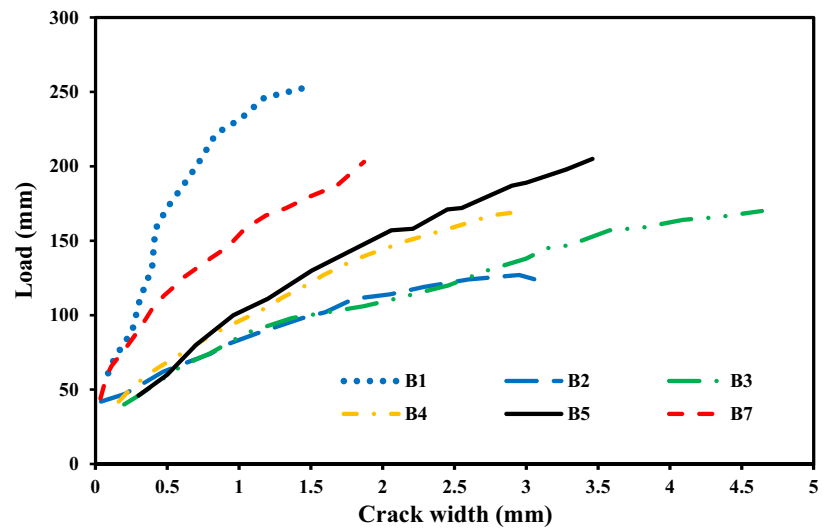

Fig. 4 Crack width of tested beams.

first shear crack appeared at a load of $40 \mathrm{kN}$, followed by the first flexural crack at $55 \mathrm{kN}$ located at mid-span. As the load increased, a diagonal crack passing through the center of the opening was formed at $90 \mathrm{kN}$. Two additional cracks formed in the top and bottom chords of the opening during the application of load. As the loading continued to progress, the cracks widened with several minor cracks appearing along the façade of the beam, as shown in Fig. 6. Finally, the beam failed due to the presence of these cracks in the bottom chords of the opening at a load of approximately $124 \mathrm{kN}$.

For strengthened beams, the bond interface is generally considered the weakest link in the element and debonding at this interface will usually experience what is known as the critical failure mode (Zhou et al. 2010).
In beam B3, the shear crack followed by the first flexural crack occurred at approximately the same load of that in beam B2. To evaluate the effect of preloading on the strengthening efficiency, the beam (B3) was strengthened without preloading. For beam B3, attaining the measurements of the first shear crack width was not feasible, due to the concealment of cracks by the fiber wrap. The first flexural cracks appeared in the constant moment region at $61 \mathrm{kN}$ (1.5 times the cracking load of beam B2). As loading progressed, the developed flexural cracks widened, and the flexural cracks stopped increasing. The specimen finally failed in a brittle manner at a load of approximately $178 \mathrm{kN}$ in the top chord of the opening at the top AFRPstrengthening sheet. At failure, a partial debonding of the fiber wrap was noted. Beams B4 and B5 were initially loaded to $50 \%$ of the control beam (B2) capacity to simulate the initial cracks. In this loading phase, the formation of cracks was very similar to that of the control beam, and at the completion of this loading phase, the load was kept without release for repairing. Before reloading up to failure, the $U$ wrap $\left(90^{\circ}\right)$ and diagonal $\left(60^{\circ}\right)$ AFRP shape (with respect to the beam axis) strengthening approaches were used for B4 and B5, respectively. Next, the cracking and ultimate loads in the second loading phase of these beams were determined, as shown in Table 4. The vertical orientation of AFRP in beam B4 proved to yield a lower performance than the diagonal orientation of AFRP seen in other strengthened beams. This is attributed to: deep beam failure action, and failure of the beams' chords due to 
Table 3 Experimental results.

\begin{tabular}{c|c|c|c|c}
\hline Specimen & First shear crack $(\mathrm{kN})$ & First flexural crack $(\mathrm{kN})$ & Failure load $(\mathrm{kN})$ & Failure mode \\
\hline \hline B1 & 69 & 100 & 251 & Shear failure \\
\hline B2 & 40 & 55 & 124 & Shear failure \\
\hline B3 & - & 61 & 178 & FRP debonding \\
\hline B4 & 40 & 65 & 208.9 & $\begin{array}{c}\text { FRP peeling and shear } \\
\text { failure }\end{array}$ \\
\hline B5 & 38 & 58 & 185.2 & $\begin{array}{c}\text { Concrete crushing and FRP } \\
\text { peeling }\end{array}$ \\
\hline B6 & 39 & 67 & 204 & $\begin{array}{c}\text { Concrete crushing and FRP } \\
\text { peeling }\end{array}$ \\
\hline
\end{tabular}

vertical cracks parallel to the FRP axis which helps for FRP peeling.

Beams B6 and B7 were initially loaded up to $70 \%$ of the control beam (B2) capacity to simulate the initial cracks. The load in Beam B6 was kept without release, whereas, the load in B7 was released to the cracking load of control beam B2. The load was then kept constant for both beams during FRP strengthening process. The diagonal AFRP strips were then used to strengthen both the upper and lower chords of these beams. After this strengthening procedure, the beams were subjected to a continuous load. It was observed that there were no critical diagonal cracks present in beams B6 and B7; the maximum crack width measured for these beams, therefore, remained minor during the entire loading history. Additionally, when compared to beam B4, no debonding failure was observed at the end of the AFRP in these beams up to the failure loads. The cracking, failure loads and modes of failure of these beams are shown in Table 3 and Fig. 6. Compared to beam B1, the reduction in shear capacity was caused by the early formation of a diagonal crack around the chords of the opening due to the stress concentration and the reduced ability of the web area to resist high shear.

\subsection{Cracking Behaviors}

A special microscope with $0.02-\mathrm{mm}$ accuracy was used to measure the crack width at different locations. The loads corresponding to the appearance and progression of cracks at the different loading stages are presented in Table 4. The first crack appeared at approximately the shear span of the beam, with, new cracks forming progressively towards the supports. Diagonal shear cracks appeared next, which were propagated downwards to the inner edge of the support and upwards to the loading point. With its appearance, the width of the shear cracks began to exceed that of those formed in the flexural zone. As load increased, the existing cracks advanced further and new cracks began to form inside the openings, which ultimately lead to the failure at the beam's chords. During the course of this study, all major cracks were inspected (visually) and their maximum widths measured and recorded up until failure. The measured crack widths against the applied load are plotted in Fig. 4.

The measured cracking width of beam B1 was approximately $0.15 \mathrm{~mm}$ at $88 \mathrm{kN}$. As loading progressed, the crack width augmented from approximately 0.33 to $1.45 \mathrm{~mm}$ at 125 and $251 \mathrm{kN}$ (failure load), respectively. In beam B2, cracks appeared early during the loading process, with a width of approximately $0.04 \mathrm{~mm}$ at a load of $40 \mathrm{kN}$. After increasing the load, the crack width increased exponentially, especially in areas near the opening. Beam B2 experienced failure in shear at $124 \mathrm{kN}$, with a maximum crack width of $3.31 \mathrm{~mm}$. The crack patterns of the remaining beams (B3B7) before strengthening showed very similar crack patterns to those in the control beam (B2); however, the maximum measured crack width for all AFRP strengthened beams was lower. Furthermore, the attained ultimate loads were much higher than that of the control beam, as illustrated in Table 3. Figure 4 shows the crack width of the tested beams.

By increasing the pre-damaged load before strengthening, the crack width increased rapidly especially during failure stage. In beam B5, lower pre-damaged loads resulted in a remarkable decrease in the crack width by 15.8 and $60 \%$ at corresponding loads of $80 \mathrm{kN}$ and $125 \mathrm{kN}$, respectively, compared to the control beam B2. When the pre-damage was increased to $70 \%$ of $\mathrm{B} 2$, the crack width increased considerably, and hence a significant reduction in the beam stiffness was recorded. At 80 and $125 \mathrm{kN}$, the crack width of specimens B6 (with pre-damages of $70 \%$ of B2) was about 7 and $9.8 \%$, respectively, and resulted in lower crack widths than those of beam B5 (with lower damage) as shown in Table 4 .

In the strengthened beams, the main flexural crack formed at a load of approximately $65 \mathrm{kN}$. After a load level corresponding to approximately $85 \%$ of the ultimate load was attained, no more flexural cracks appeared, and only widening of the existing vertical flexural cracks could be observed. Next, the beam started to fail, mainly by brittle shear failure, in which the diagonal shear cracks that formed at the top and bottom chords of the beams led to concrete crushing or AFRP debonding or peeling. Most of the failures 


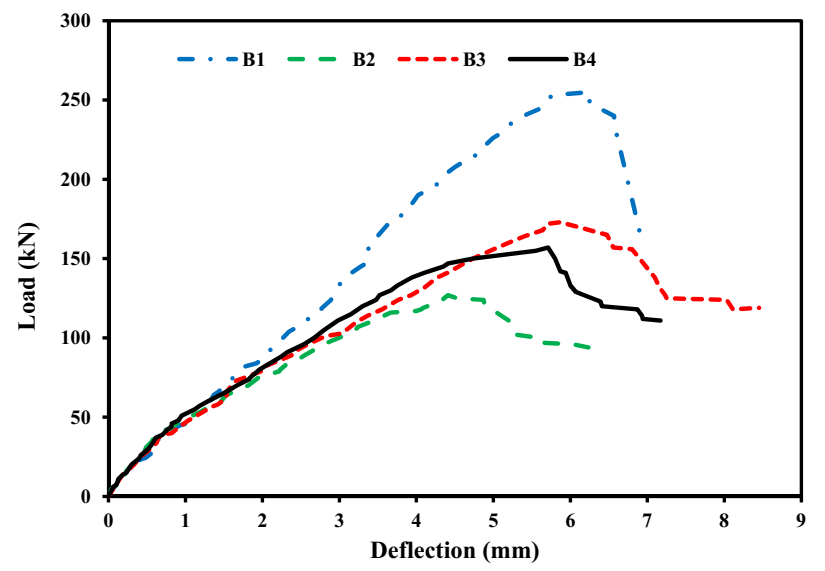

(a)

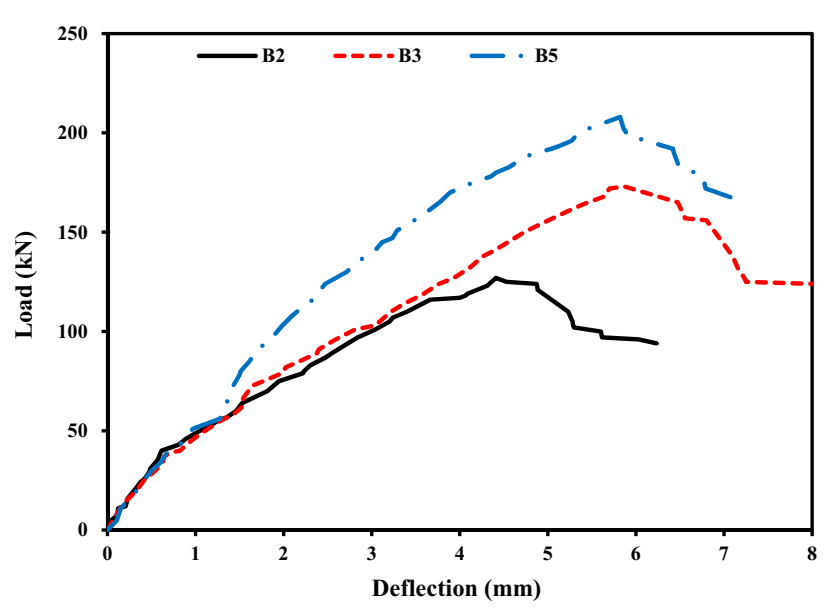

(b)

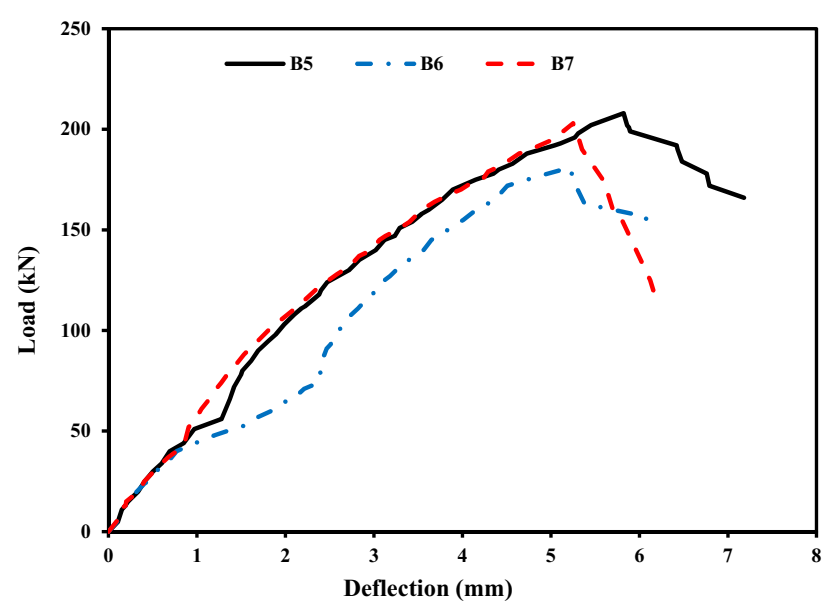

(c)

Fig. 5 Load deflection relationship of the tested beams a B1, $\mathrm{B} 2$, B3 and B4, b B2, B3 and B5, and $\mathbf{c}$ B5, B6 and B7.

of the tested beams occurred in the concrete thin layer adjacent to the sheet (in direct contact with the FRP sheet), not in the adhesive epoxy (Fig. 6) (Hussein et al. 2013).

\subsection{Deflection Behavior}

To investigate the deflections and stiffness of the reinforced concrete beams with openings strengthened with AFRP sheets, the load deflection curves were studied. Four
LVDTs were used to measure the displacement: one at the top of the beam located at the mid-span and three at the bottom of the beam (one at the mid-span and two under the loading points) (Fig. 3a). The three LVDTs at the bottom read almost the same displacement values, and even the two LVDTs at the top and bottom (mid-span) exhibited no clear difference. The mid-span deflection at the maximum load for the tested reinforced concrete beams with the opening is illustrated in Fig. 5. The load deflections of the beams tested can therefore be generalized to those of typical RC beams, which like the beams tested, fail mainly due to shear. All beams demonstrated a nearly linear trend up to approximately $65 \%$ of the failure load.

From Fig. 5, the changes in the slope of the curves indicate that the cracking of the concrete has occurred and the AFRP sheet started to carry load. The ultimate loads of the test beams proved to be different from the control beam, this difference is dependent upon the loading behavior. After a load of $65 \%$ of the ultimate load was applied, the beams experienced a reduction in stiffness, and soon after, complete failure. Strengthening of pre-cracked beams showed increases in the initial stiffness, ultimate load, and deflection, compared to the equivalent control beam. The strengthening of beams after pre-damage ultimately leads to an increase in the external force required to produce cracks in the concrete at ultimate. Additionally, the experiments conducted showed that by increasing the pre-damage load, a decrease in the ultimate load by $11 \%$ in beam B6 was experienced when compared to the equivalent pre-damaged beam B5.

For pre-damaged strengthened beams, it was observed that the stiffness of the beams were increased after strengthening. This strengthening restrained the cracks that were previously generated due to the application of loads prior to the FRP application, which reduced the magnitude of displacement between the two halves of the main crack by transferring the failure to the FRP sheet.

\subsection{Strain Distribution}

The results of some failed strain gauges during testing were discarded due to the erroneous data that they provided. The strain gauges locations are illustrated in Fig. 3.

\subsubsection{Reinforcement Strain}

The main steel strain was recorded at the mid-span and at the region surrounding the openings. For all beams, the strains along the reinforcement bars varied in a manner similar to the bending moment up to the formation of the diagonal shear crack. Figure 7 shows the strain distribution of the longitudinal steel in the tension face at different loading level. The linear strain distribution in the longitudinal steel was observed and did not reach its ultimate strain until beam failure; which was attributed to the shear failure of the beams and early contribution of the FRP. Finally, by load increasing, the load-strain curves slope increased with a linear trend till failure of the concrete.

Figure 8 shows the load versus vertical reinforcement strain for the tested beams. The vertical steel strain was measured around the openings in two stirrups (before and 

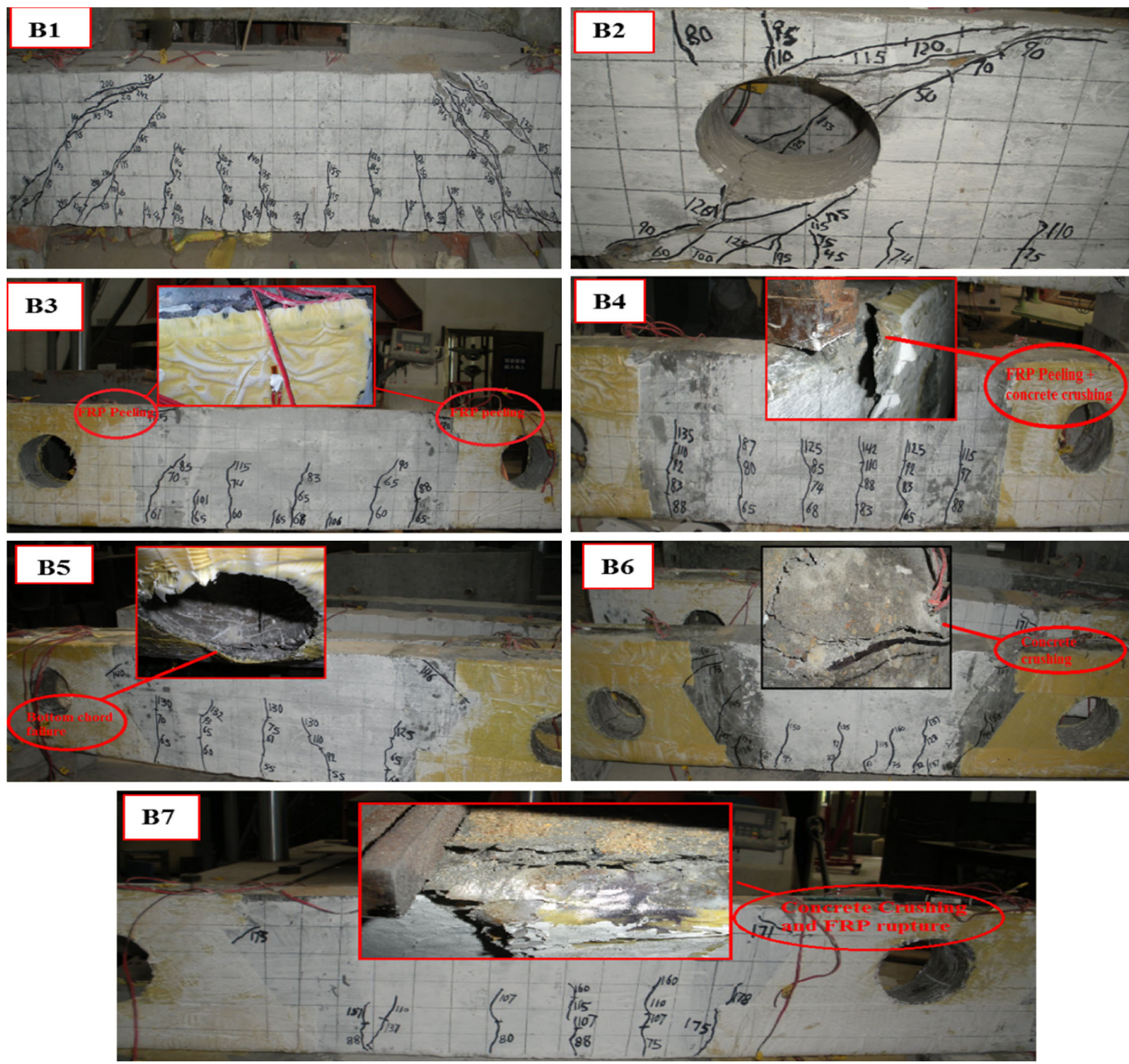

Fig. 6 Typical failure observed for both un-strengthened and repaired beams (B1-B7).

Table 4 Maximum shear crack width $(\mathrm{mm})$ at $80,125,150 \mathrm{kN}$, and at failure load.

\begin{tabular}{c|c|c|c|c}
\hline Beam & At $80 \mathrm{kN}$ & At $125 \mathrm{kN}$ & At $150 \mathrm{kN}$ & At failure \\
\hline \hline B1 & 0.15 & 0.33 & 0.39 & 1.45 \\
\hline B2 & 1.01 & 3.31 & - & 3.31 \\
\hline B3 & 0.84 & 2.46 & 3.38 & 4.65 \\
\hline B4 & 0.65 & 1.51 & 2.068 & 2.96 \\
\hline B5 & 0.85 & 1.32 & 1.94 & 3.45 \\
\hline B6 & 0.91 & 1.45 & 2.03 & 3.00 \\
\hline B7 & 0.20 & 0.56 & 0.95 & 1.87 \\
\hline
\end{tabular}

after the opening). The load versus longitudinal reinforcement strain for the tested beams is shown in Fig. 7.

From Fig. 8, the strain values before first crack was smaller and almost close to the vertical axis with values near to zero. In loads that generated approximately $80 \%$ of failure load for the control beam, the slope of the strain distribution experienced an increase, which was attributed to the increase of the load that was carried by the vertical reinforcement. 


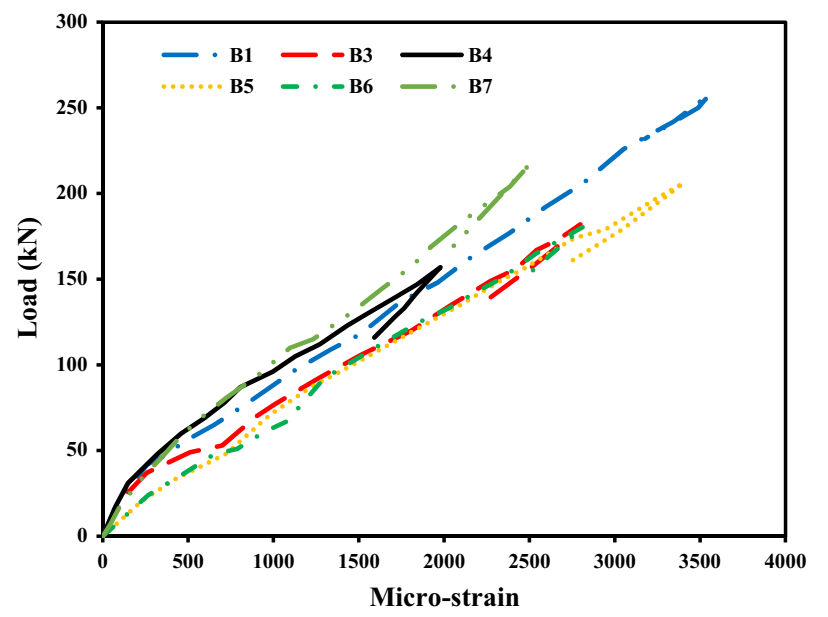

(a)

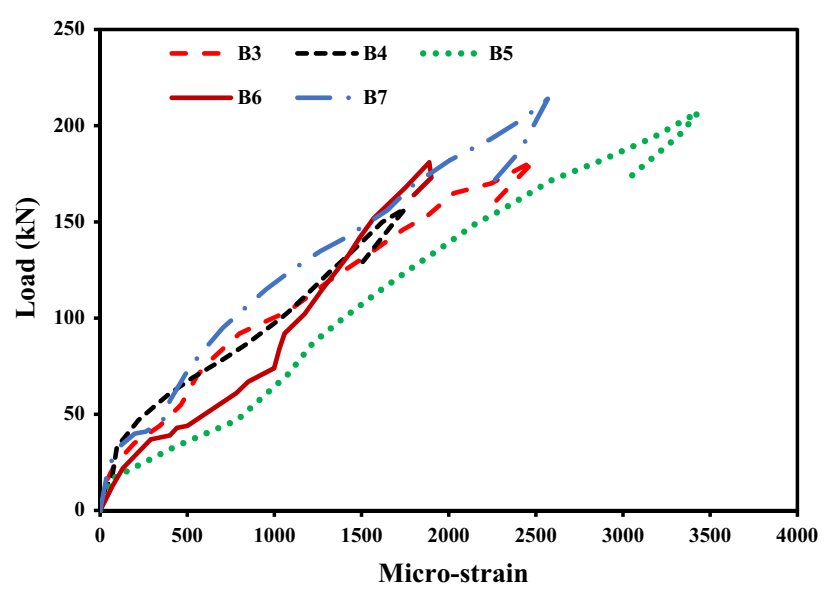

(b)

Fig. 7 Tensile steel strain a at mid-span (T2) and b below the opening at the bottom chord (T1).

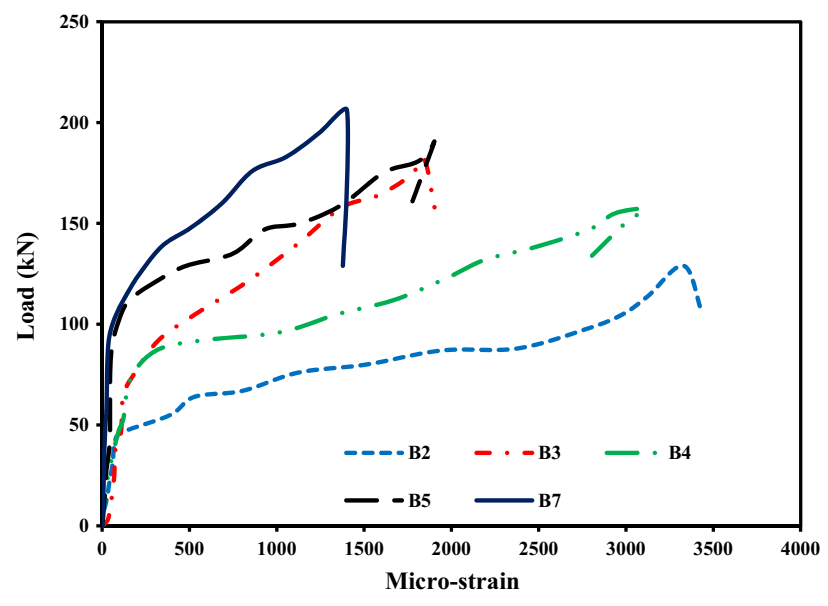

Fig. 8 Stirrups steel (vertical reinforcement) strain (S2).

Lately, the curve had started to show some reasonable inclination, this means that the strain value which corresponding to the applied load is big compared to previous loading stages increment.

According to the strain values predicted in Fig. 8, the transversal reinforcement starts to carry loads at almost 48 $\mathrm{kN}$ for the case of the control beams, at $90 \mathrm{kN}$ for beams B3

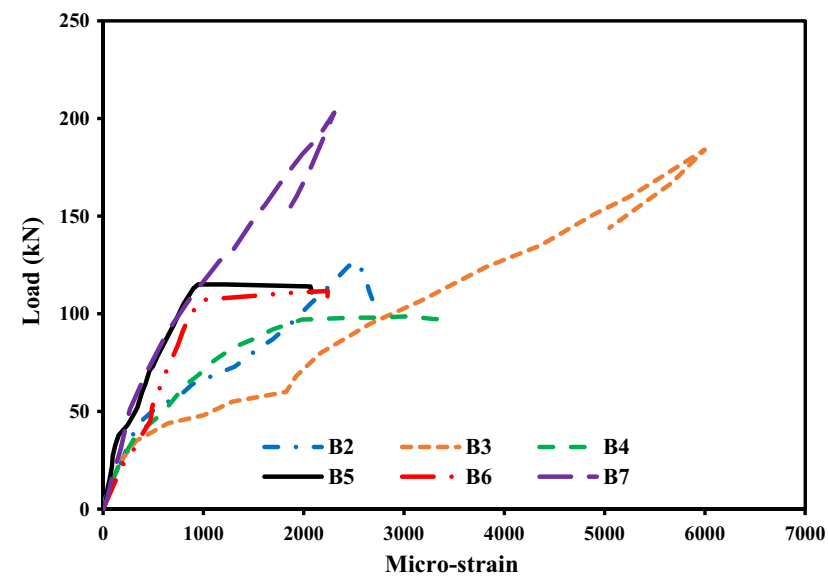

Fig. 9 Concrete strain in the bottom of the beams at midspan (C4).

and B4, and at loads more than $100 \mathrm{kN}$ for the beams B5 and B7. This signifies that the stirrup steel present in the tested beams have yet to reach their yielding points before concrete failure has occurred. This is mainly due to the presence of AFRP, and its ability to carry loads once the structural integrity of the element begins to weaken (Ferreira et al. 2013).

\subsubsection{Concrete Strain}

The strains in the concrete were measured using electricalresistance strain gauges with gauge lengths of $100 \mathrm{~mm}$, as illustrated above in Fig. 3. Figure 9 shows the load-strain plots for the tested specimens. It can be observed that the strains at low load levels appeared to increase linearly after increasing non-linearly until the first diagonal cracking load was reached. Accordingly, it has been projected that the concrete will fail, as such the AFRP will carry the bulk of the load. After this point, the values increased gradually up to failure.

Some of the strain values in Fig. 9 were more than 2000 micro, this may be attributed to that when the steel start to yield explains the large concrete strains. Furthermore, may be due to several factors such as cracks may be occurring at the interfaces between the cement and aggregate, due to their differences in elastic modulus, thermal coefficient of expansion, and response to change in moisture content when the concrete is hardened (Damian et al. 2001).

\subsubsection{FRP Strain}

The positions of the FRP strain gauges are given in Fig. 3b. The shear force-strain curves for the externally bonded AFRP sheets in the shear spans where failure occurred are shown in Fig. 10. In the first stage, the FRP sheets started to resist the further opening of the existing shear cracks at the inception of the final reloading stage, and they continued to develop tensile strain with an increased load up to approximately the peak loads. Then, the sheets started to peel off or debond, or the concrete was crushed. Figure 10 shows that at any load before first crack, the beams shows smaller strain values. Till the first crack, the FRP has not taken much load as the strain is almost close to 


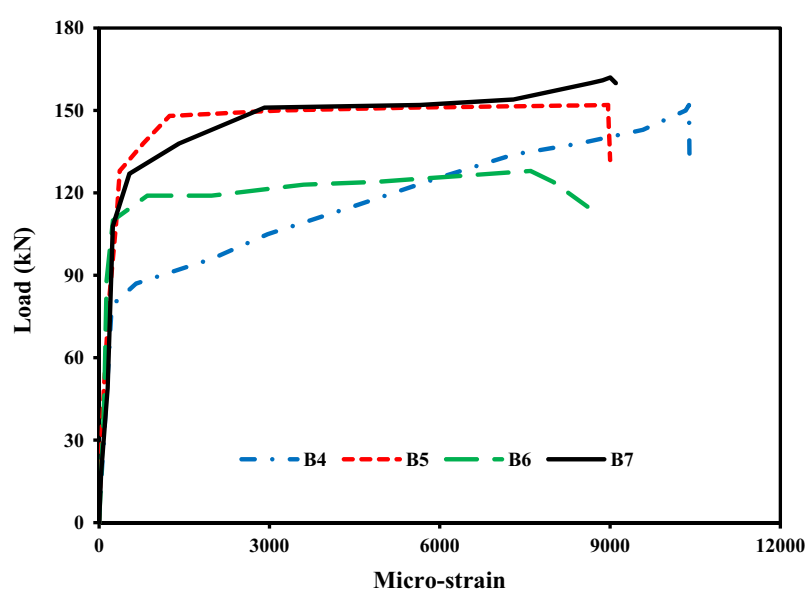

(a)

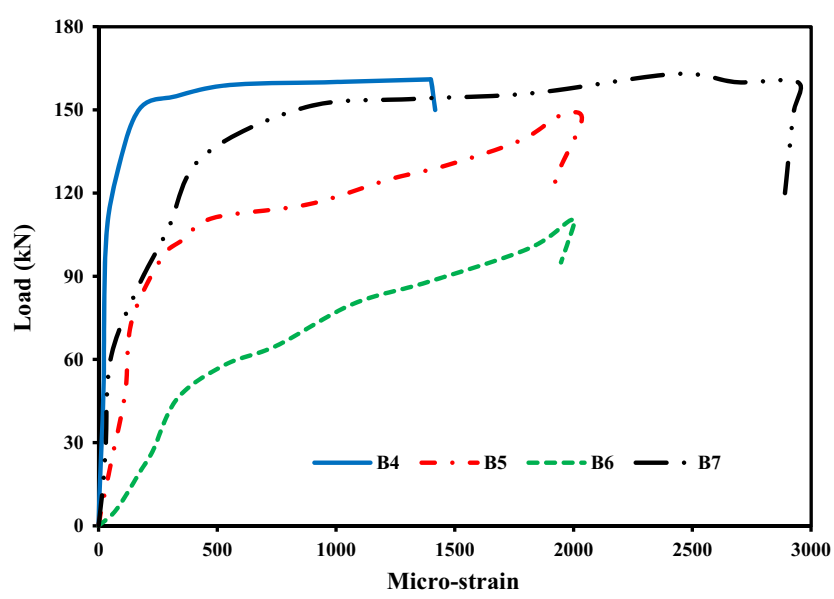

(C)

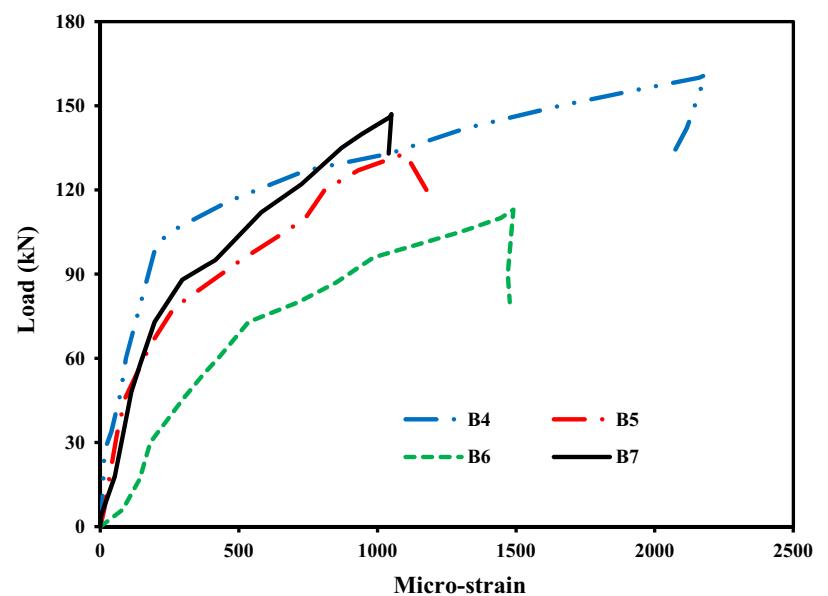

(b)

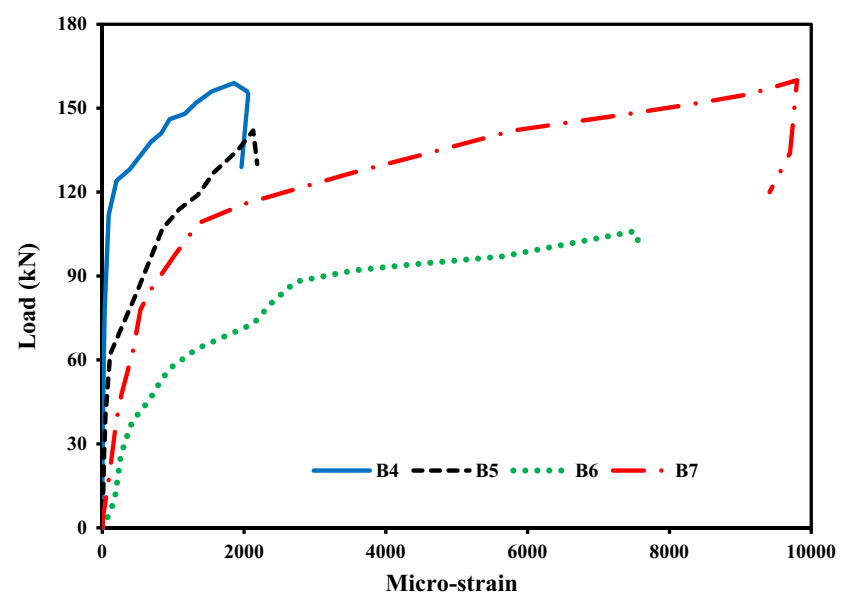

(d)

Fig. 10 AFRP sheet strain a F1, b F2, c F3, and d F4.

zero in this stage and the curve is almost close to the vertical axis. From this stage, the FRP starting to take load, by the fact that the curve had started to show some reasonable inclination. From this point it was clear that the curve has taken a slope which indicates the FRP has started to take substantial load.

As seen from Figs. 10a and 10d, it was observed that the ultimate tensile strain from openings' sides in F1 and F4 which lie in the shear path (line connected the load point and the support) equal to approximately $10,000 \mu \varepsilon$, which is greater than the tensile strain at the beams' chords (F2 and F4) which is equal to approximately $2000 \mu \varepsilon$. This increase in the tensile strain is attributed to the concentration of the stresses along the shear path (line connecting the load point and the support) due to the relative displacement between the two of the main cracks.

\section{Performance of the Current Analytical Equations Used in this Study}

Shear strength and shear forces in RC beams following the ACI approach (ACI 318 2014; Mansur 1998) was able to develop the following equations for beam type failure.

$$
\begin{gathered}
V_{n}=V_{c}+V_{s} ; \quad V_{c}=\left(0.158 \sqrt{f_{c}} b d\right. \\
V_{s}=V_{s t}+V_{s l}=\left(\frac{A_{s t} f_{y s t}}{b s}+\frac{17.24 A_{s l}}{b a}\right) b d \\
V_{n}=\left(0.158 \sqrt{f_{c}}+\frac{A_{s t} f_{y s t}}{b s}+\frac{17.24 A_{s l}}{b a}\right) b d
\end{gathered}
$$

Equation (1) can be used for calculating shear strength of $\mathrm{RC}$ beam containing opening as proposed by Mansur (2006):

$$
V_{n}=\left(0.158 \sqrt{f_{c}}+\frac{A_{s t} f_{y s t}}{b s}+\frac{17.24 A_{s l}}{b a}\right) b\left(d_{v}-d_{0}\right)
$$

where, $V_{c}$ and $V_{s}$ are the contribution of the concrete and steel reinforcement respectively; $f_{c}$ is the concrete strength; $b$ is the beam width; $d$ is the effective depth; $d_{o}$ is the depth of opening; $d_{v}$ is the distance between the centroids of extreme tension and compression reinforcement layers; $s$ is the stirrup spacing; $A_{s t}$ is the area of stirrups; $A_{d}$ is the cross-sectional area of the diagonal reinforcement within the failure surface; $f_{y s t}$ is the yield strengths of the stirrups reinforcement; $A_{s l}$ is area of tension steel and $a$ is shear span. 
Table 5 Comparison of the experimental and analytical results.

\begin{tabular}{c|c|c|c|c|c|c|c}
\hline Beam & $V_{c}(\mathrm{kN})$ & $V_{s}(\mathrm{kN})$ & $V_{f}(\mathrm{kN})$ & $V_{n}(\mathrm{kN})$ & $P_{\text {theo. }}(\mathrm{kN})$ & $P_{\text {exp. }}(\mathrm{kN})$ & $\frac{P_{\text {exp. }}}{P_{\text {theo. }}}$ \\
\hline \hline B1 & 33.71 & 73.27 & - & 107 & 214 & 251 & 1.17 \\
\hline B2 & 16.9 & 36.638 & - & 53.8 & 108 & 125 & 1.15 \\
\hline B3 & 16.90 & 36.638 & 55.54 & 109 & 218 & 178 & 0.82 \\
\hline B4 & 16.90 & 36.638 & 55.54 & 109 & 218 & 160 & 0.74 \\
\hline B5 & 16.90 & 36.638 & 75.87 & 129.4 & 258.8 & 209 & 0.82 \\
\hline B6 & 16.90 & 36.638 & 75.87 & 129.4 & 258.8 & 185 & 0.71 \\
\hline B7 & 16.90 & 36.638 & 75.87 & 129.4 & 258.8 & 204 & 0.80 \\
\hline
\end{tabular}

$P_{\text {theo. }}$ and $P_{\text {exp. }}$ are ultimate load for theoretical and experimental tests, respectively.

\subsection{FRP Contribution}

The contribution of the FRP sheet to shear strength of RC beams is based on the orientation of the fiber and an assumed crack pattern (ACI-440.2R-08 2008). The shear strength provided by the FRP contribution can be determined by calculating the force resulting from the tensile stress in the FRP across the assumed crack. The shear contribution of the FRP shear reinforcement is given by the following equations (ACI-440.2R-08 2008):

$$
\begin{aligned}
& V_{f}=\frac{A_{f} f_{f e}(\sin \alpha+\cos \alpha) d_{f}}{s_{f}} \\
& A_{f}=2 n t_{f} w_{f} \\
& f_{f e}=\varepsilon f_{f e} \cdot E_{f}
\end{aligned}
$$

Shear capacity of FRP RC beam can be determined from Eq. (7).

$$
\phi V_{n}=\phi\left(V_{c}+V_{s}\right)+0.7 V_{f}
$$

where $\phi=$ the strength-reduction factor required by ACI that for shear strengthening of concrete elements has a value of 0.85 (Khalifa et al. 1998); $s_{f}$ is the spacing of the wet layup strips of FRP sheets; and $A_{f v}$ is the area of FRP shear reinforcement within spacing, $s_{f} ; t_{f}, n$, and $w_{f}$ are the thickness of a layer, the number of layers per strip, and the width of the strips, respectively. If continuous or one FRP sheets are used, the width of the strip, $w_{f}$ and the spacing of the strips, $s_{f}$ should be equal $\left(s_{f}=w_{f}\right)$ (Khalifa et al. 1998).

The effective stress in the FRP, $f_{f e}$ obtained multiplying the elasticity modulus of the FRP, $E_{f}$ by the effective strain

$$
\varepsilon_{f e}=k_{v} \varepsilon_{f u} \leq 0.004 \text { (for U-wrap) }
$$

where, $k_{\mathrm{v}}$ is a bond-reduction coefficient that is a function of the concrete strength, the type of wrapping scheme used, and the stiffness of the FRP.

$$
\begin{aligned}
& k_{v}=\frac{k_{1} k_{2} L_{e}}{11,900 \varepsilon_{f u}} \leq 0.75 \\
& L_{e}=\frac{23,300}{\left(n t_{f} E_{f}\right)^{0.58}}
\end{aligned}
$$

$$
\begin{aligned}
& k_{1}=\left(\frac{f_{c}}{27}\right)^{0.67} \\
& k_{2}=\frac{\left(d_{f}-L_{e}\right)}{d_{f}}(\text { for U wrap) }
\end{aligned}
$$

where, $d_{f}$ is the depth of FRP shear reinforcement, $k_{2}$ is modification factor applied to $k_{v}$ to account for the wrapping scheme, $L_{e}$ is active bond length of FRP laminate, and $k_{1}$ is modification factor applied to $k_{v}$ to account for the concrete strength.

In Table 5, the values obtained using these equations were compared to those obtained experimentally. For beam B6, the ACI equation has underestimated the shear strength of FRP contribution for RC beams subjected to high damage (70\% of B2) by approximately $28 \%$ error band. For beam B4, an orientation of vertical FRP sheet crossed by the shear crack might have caused the low value of the FRPstrengthening-sheet contribution, subsequently the strengthening sheet debonded prematurely at a relatively low magnitude of applied load compared to that calculated from ACI 440.2R-08 (2008) equation by approximately 26\%. This variation between analytical and experimental results may be due to the residual strain in the concrete before strengthening; the ACI 440.2R-08 equation, is therefore, unsuitable for the estimation of the shear capacity of high damaged $\mathrm{RC}$ beams under sustained loads.

According to the results obtained from the present experimental work, the design value of the contribution of the FRP shear reinforcement can be estimated using the recommendations proposed by ACI guidelines (ACI440.2R-08 2008; ACI-014 2014) for damage levels not exceeding a $70 \%$ capacity of equivalent unstrengthened beams.

\section{Conclusion}

Experiments were performed to study the effects of different pre-cracking loads on the shear strength of RC deep beams with openings. Based on the experimental results and discussions, the following conclusions could be drawn, 
(1) The pre-cracked RC deep beams with openings strengthened by AFRP sheets displayed a higher level of stiffness and ductility; with reductions in the crack width between 25.6 and $82.7 \%$ at failure load when compared with the control beam. This is predominately due to limiting the development of shear cracks by using the epoxy resin prior to the application of the AFRP strengthening strip. This is demonstrated most clearly in beam B7, which was loaded up to $70 \%$ and reduced to cracking loads of those loads subjected to B2.

(2) Damage levels have an effect on the ultimate capacity of the reinforced concrete deep beam strengthened with AFRP sheet by a decrease in failure load of approximately $11.5 \%$, when the damage level was increased from 50 to $70 \%$ of control beam B2. Beam B7 failed with load capacities lower than that of beam B5 by $2.5 \%$, this is attributed to the residual stress in beam B7.

(3) All of the strengthened specimens exhibited higher capacities than the equivalent unstrengthened control beams, with capacity enhancements ranging from 21.8 to $66.4 \%$, thus confirming the potential effectiveness of the FRP sheets.

(4) Strengthening the more damaged RC deep beams with openings by AFRP sheets decreased the mid-span deflection at the ultimate load by $22.5 \%$ when compared with the control beam. This is primarily due to the AFRP's ability to carry additional loads when the concrete begins to experience failure and its ability to limit further development of exiting cracks.

(5) AFRP strengthening of pre-cracked RC deep beam with opening can enhances a beam's capacity (Fig. 5) and stiffness after repairing, and decreases the crack width spatially (as seen in beam B7). Furthermore, loading the beams to less than their cracking loads prior to the application of the FRP strengthening had almost no effect on the repair efficiency (El-Ashkar et al. 2012).

(6) The orientation of AFRP sheets used for shear strengthening (reducing the stress concentration on the top and bottom chords of the opening) and the crack width both play a significant role in the behavior of RC beams with openings. The AFRP sheets installed at $60^{\circ}$ to the axis of the beam are found to be most efficient for shear-strength enhancements, whereas the vertical AFRP sheets are less effective (B4 and B5).

\section{Open Access}

This article is distributed under the terms of the Creative Commons Attribution 4.0 International License (http://creativecommons.org/licenses/by/4.0/), which permits unrestricted use, distribution, and reproduction in any medium, provided you give appropriate credit to the original author(s) and the source, provide a link to the Creative Commons license, and indicate if changes were made.

\section{References}

Abdulhameed, S. S., Wu, E., \& Ji, B. (2013). Mechanical prestressing system for strengthening reinforced concrete members with prestressed carbon-fiber-reinforced polymer sheets. Journal of Performance of Constructed Facilities, 29(3), 04014081.

ACI-014. (2014). Building code requirements for structural concrete and commentary. Farmington Hills, MI.

ACI-440.2R-08. (2008). Guide for the design and construction of externally bonded FRP systems for strengthening concrete structures. Farmington Hills, MI.

Ashour, A. F., \& Rishi, G. (2000). Tests of reinforced concrete continuous deep beams with web openings. Structural Journal, 97(3), 418-426.

Aykac, B., Kalkan, I., Aykac, S., \& Egriboz, Y. E. (2013). Flexural behavior of RC beams with regular square or circular web openings. Engineering Structures, 56, 2165-2174.

Campione, G., \& Minafò, G. (2012). Behaviour of concrete deep beams with openings and low shear span-to-depth ratio. Engineering Structures, 41, 294-306.

Chaallal, O., Shahawy, M., \& Hassan, M. (2002). Performance of reinforced concrete T-girders strengthened in shear with carbon fiber-reinforced polymer fabric. ACI Structural Journal, 99(3), 335-343.

Damian, K., Thomas, M., Solomon, Y., Kasidit, C., \& Tanarat, P. (2001). Finite element modeling of reinforced concrete structures strengthened with FRP laminates. Salem, OR: Report for Oregon Department of Transportation.

Deborah, D. C. (1994). Carbon fiber composites (1st ed.). Waltham, MA: Butterworth-Heinemann Publisher.

Dias, S. J., \& Barros, J. A. (2008). Shear strengthening of T cross section reinforced concrete beams by near-surface mounted technique. Journal of Composites for Construction, 12(3), 300-311.

Dirar, S., Lees, J. M., \& Morley, C. (2013). Phased nonlinear finite-element analysis of precracked RC T-beams repaired in shear with CFRP sheets. Journal of Composite for Construction, 17(4), 476-487.

El Maaddawy, T., \& Sherif, S. (2009). FRP composites for shear strengthening of reinforced concrete deep beams with openings. Composite Structures, 89(1), 60-69.

El-Ashkar, N., A. Morsy, \& K. Helmi, (2012). FRP repair technique for RC beams pre-damaged in shear. In Proceedings of 14th International Structural faults and repair. Edinburgh: Engineering Technics Press.

Etman, E. (2011). Strengthening of T-section RC beams in shear using CFRP. In Proceedings of concrete solutions. 14th international conference on concrete repair. Dresden, Germany.

Ferreira, D., Oller, E., Marí, A., \& Bairán, J. (2013). Numerical analysis of shear critical RC beams strengthened in shear with FRP sheets. Journal of Composites for Construction, 17(6), 04013016.

Hawileh, R. A., El-Maaddawy, T. A., \& Naser, M. Z. (2012). Nonlinear finite element modeling of concrete deep beams 
with openings strengthened with externally-bonded composites. Materials and Design, 42, 378-387.

Hoult, N. A., \& Lees, J. M. (2009). Modeling of an unbonded CFRP strap shear retrofitting system for reinforced concrete beams. Journal of composites for construction, 13(4), 292-301.

Hussain, Q., \& Pimanmas, A. (2015). Shear strengthening of RC deep beams with openings using Sprayed Glass Fiber Reinforced Polymer Composites (SGFRP): Part 1. Experimental study. KSCE Journal of Civil Engineering, 19(7), 2121-2133.

Hussein, M., Afefy, H. M. E.-D., \& Khalil, A.-H. A.-K. (2013). Innovative repair technique for $\mathrm{RC}$ beams predamaged in shear. Journal of Composite for Construction, 17(6), 04013005

Khalifa, A., Gold, W. J., Nanni, A., \& Abdel Aziz, M. I. (1998). Contribution of externally bonded FRP to shear capactiy of RC flexural members. Journal of Composites for Construction, 2(4), 195-202.

Kim, S., \& Vecchio, F. J. (2008). Modeling of shear-critical reinforced concrete structures repaired with fiber-reinforced polymer composites. Journal of Structural Engineering, 134(8), 1288-1299.

Lin, X., \& Zhang, Y. (2013). Bond-slip behaviour of FRPreinforced concrete beams. Construction and Building Materials, 44, 110-117.

Mansur, M. (1998). Effect of openings on the behaviour and strength of $\mathrm{R} / \mathrm{C}$ beams in shear. Cement \& Concrete Composites, 20(6), 477-486.

Mansur, M.A. (2006). Design of Reinforced Concrete Beams with Web Openings. In Proceedings of the 6th ASI-pacific Structural Engineering and Construction Conference (APSEC 2006). 5-6 September 2006, Kuala Lumpur, Malaysia.

Mansur, M., \& Alwis, W. (1984). Reinforced fibre concrete deep beams with web openings. International Journal of Cement Composites and Lightweight Concrete, 6(4), 263-271.
Mansur, M., Tan, K.-H., \& Wei, W. (1999). Effects of creating an opening in existing beams. Structural Journal, 96(6), 899-905.

Osman, B. H., Wu, E., Ji, B., \& Abdulhameed, S. S. (2016). Shear behavior of reinforced concrete (RC) beams with circular web openings without additional shear reinforcement. KSCE Journal of Civil Engineering. doi: 10.1007/s12205-016-0387-7.

Richardson, T., \& Fam, A. (2014). Modulus effect of bonded CFRP laminates used for repairing preyield and postyield cracked concrete beams. Journal of Composite for Construction, 18(4), 04013054.

Shanmugam, N. E., \& Swaddiwudhipong, S. (1988). Strength of fibre reinforced concrete deep beams containing openings. International Journal of Cement Composites and Lightweight Concrete, 10(1), 53-60.

Singh, S. B. (2013). Shear response and design of RC beams strengthened using CFRP laminates. International Journal of Advanced Structural Engineering (IJASE), 5(1), 1-16.

Torunbalci, N. (2002). Behaviour and design of large rectangular openings in reinforced concrete beams. Architectural Science Review, 45(2), 91-96.

Vecchio, F. J., \& Bucci, F. (1999). Analysis of repaired reinforced concrete structures. Journal of Structural Engineering, 125(6), 644-652.

Yang, K.-H., Eun, H.-C., \& Chung, H.-S. (2006). The influence of web openings on the structural behavior of reinforced high-strength concrete deep beams. Engineering Structures, 28(13), 1825-1834.

Zhang, Z., Hsu, C.-T. T., \& Moren, J. (2004). Shear strengthening of reinforced concrete deep beams using carbon fiber reinforced polymer laminates. Journal of Composites for Construction, 8(5), 403-414.

Zhou, Y.-W., Wu, Y.-F., \& Yun, Y. (2010). Analytical modeling of the bond-slip relationship at FRP-concrete interfaces for adhesively-bonded joints. Composites Part B Engineering, 41(6), 423-433. 